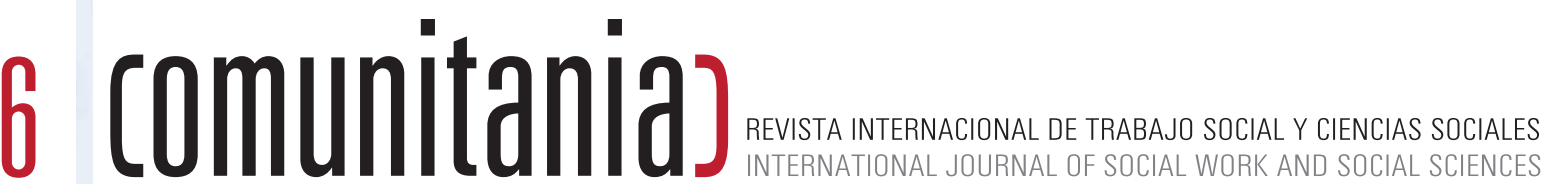

IGNASI BRUNET ICART | JOAN RODRÍGUEZ SOLER | BEATRIZ ESCUDERO BERZAL | PALOMA SERRANO POSTIGO LUIS MANUEL RODRÍGUEZ OTERO | MARTHA LETICIA CABELLO GARZA | MARÍA CONCEPCIÓN ARROYO RUEDA 


\title{
Empresas spin-off y género: diferencias entre hombres y mujeres en la creación de empresas de base tecnológica Spin-off and gender: differences between men and women in the creation of technology-based companies
}

\author{
Ignasi Brunet lcart Y y Joan Rodríguez Soler** \\ * Universidad Rovira i Virgili . Ignasi.Brunet@urv.cat \\ ** Universidad Rovira i Virgili. Juan.Rodriguez@urv.cat
}

\begin{abstract}
Abstrac:
This article addresses to the effects of sexual division of labour on the creation of self employment in the specific context of knowledge transfer companies, particularly in university spin-off. The results described here are based on a study funded by the Catalan Women's Institute, which seeks to provide continuity to other research that affect the relationship between entrepreneurship and gender. The aim of this paper is to study the differences between men and women entrepreneurs and see what factors influence their trajectories. The focus of the analysis is placed on the differences that the sexual division of labour results in an activity as self-employment, focusing on two specific areas of this: the initial moment of creation of a company and in the context of high-tech companies where innovation and research, rather than added value, are the reason for such business initiatives.
\end{abstract}

Keywords: entrepreneurship, spin-off, sexual division of labour.

\section{Resumen:}

Este artículo aborda los efectos de la división sexual del trabajo sobre la creación de empleo por cuenta propia en el marco específico de las empresas de transferencia de conocimiento, particularmente en las empresas spin-off universitarias. Los resultados aquí descritos parten de un estudio, financiado por el Instituto Catalán de la Mujer, que intenta dar continuidad a otras investigaciones que inciden en la relación entre emprendeduría y género. El objetivo de este artículo pasa por estudiar las diferencias entre los hombres y mujeres emprendedores y observar qué factores inciden en sus trayectorias diferenciadas. El foco del análisis, pues, se pone en las diferencias que la división sexual del trabajo provoca en una actividad como el trabajo por cuenta propio, incidiendo en dos ámbitos concretos de éste: el momento inicial de creación de una empresa y en el contexto de empresas altamente tecnológicas donde la innovación y la investigación, más que un valor añadido, son la razón de ser de dichas iniciativas empresariales.

Palabras clave: emprendeduría, spin-off, división sexual del trabajo. 


\section{Article info:}

Received: 16/05/2012 / Received in revised form: 25/06/2013

Aceppted: 01/07/2013 / Published online: 15/07/2013

DOI: http://dx.doi.org/10.5944/comunitania.6.1

\section{Introducción}

En las últimas décadas se ha institucionalizado el discurso relativo al papel de las universidades en la economía basada en el conocimiento, en el sentido de que en esta nueva economía las universidades están obligadas a cambiar sus procesos de gestión, es decir, a manejar de forma empresarial, comercializando y/o explotando económicamente los resultados de sus investigaciones, ya sea en forma de patentes, alianzas estratégicas con empresas o con la creación de spin-offs universitarias.

Se asume, en este marco, que las universidades como universidades emprendedoras resultan ser agentes centrales, mediante la creación de iniciativas académicas, en la promoción de los cambios tecnológicos y la innovación (Clark 1998, Etzkowitz et al. 2000; Godin y Gingras 2000; Audretsch et al. 2012; Nelles i Vorley 2011; D'Este i Perkmann 2011). Esta promoción se ajusta a una de las prioridades de la actual estrategia de desarrollo regional y local, como es el fomento de territorios con capacidad competitiva, estrategia centrada en estimular la innovación, la capacidad emprendedora y la flexibilidad del sistema productivo, para conseguir ventajas competitivas que los posicione mejor frente a otros territorios, como resultado de combinar el desarrollo de recursos endógenos con el fomento y la captación de recursos y actividades del exterior. Uno de los objetivos para conseguir la producción de conocimientos económicamente valiosos, y la aplicación de estos conocimientos en el crecimiento y la competitividad, es que las universidades fomenten la creación de nuevas iniciativas empresariales en el marco de la transferencia de conocimiento y/o tecnologías desde los centros universitarios hacia dichas iniciativas.

En este contexto, el proceso de transferencia de conocimiento desde la Universidad hacia el mundo empresarial contiene dos vértices de acción. El primero, el de la investigación, tanto la básica como, especialmente, la aplicada. El segundo, el de la emprendeduría o, si se prefiere, el fomento del espíritu emprendedor, el cual hace referencia al momento inicial de creación de una iniciativa empresarial y que se compone de diferentes fases tales como la gestación y desarrollo de la idea, la formalización e inicio del negocio y la posterior consolidación inicial. En ambos planos la presencia de hombres es superior a la de mujeres, aunque en los últimos años la presencia de mujeres en el ámbito universitario y/o investigador ha aumentado. Pero este aumento se produce en unos ámbitos (el de la universidad y la empresa) tradicional y mayoritariamente masculinos. La pregunta que se plantea es evidente: ¿se está produciendo un aumento de la presencia de las mujeres en la creación de este tipo de empresas?, ¿en qué medida?, ¿bajo qué características? 
Este artículo presenta los resultados de una investigación en la que se contextualiza el discurso y las prácticas de creación de empresas spin-off en el marco de la desigualdad de género. Esta investigación busca analizar dichas empresas generadas en y por las universidades catalanas y pretende conocer si las mujeres y hombres disfrutan de las mismas oportunidades a la hora de crear este tipo de empresas. Este objetivo se puede formular en otros términos en forma de interrogante: ¿Por qué hay una mayor presencia masculina tanto en la generación de las empresas spin-off como en su desarrollo posterior? La hipótesis que formulamos para explicar esta presencia desigual de hombres y mujeres es la persistencia de la división sexual del trabajo que se traduce en que los hombres tengan una mayor orientación al logro personal de metas económicas en el mercado, mientras que en el caso de las mujeres esta orientación se ve restringida por el hecho de ocupar un papel central en el trabajo reproductivo. Los resultados aquí descritos intentan dar continuidad a otras investigaciones que inciden en la relación entre emprendeduría y género. El objetivo, por tanto, es el de verificar si las diferencias encontradas en la creación de empleo por cuenta propia según el género también se manifiestan en la creación de empresas spin-off (Brunet, Belzunegui y Valls 2009).

Otros objetivos de esta investigación son: analizar la trayectoria académica y profesional previa de hombres y mujeres para observar los efectos sobre la creación de spin-offs, indagar sobre las relaciones entre trabajo productivo y trabajo reproductivo y su incidencia sobre la creación de estas iniciativas, y analizar los efectos de la variable género sobre la gestación del capital cultural, económico y el desarrollo del capital relacional funcional en la creación y desarrollo de estos negocios.

\section{Elementos teóricos de la investigación}

\subsection{Desarrollo local, innovación y universidades emprendedoras}

En las últimas décadas la innovación es el concepto que más se utiliza para explicar los procesos de movilización del desarrollo (OCDE 1999; 2000). En el marco de estos procesos, y después de la hegemonía de los enfoques de desarrollo exógeno, centrados en los espacios y los Estados nacionales (Brunet y Böcker 2007; 2008; 2010; Brunet y Cincunegui 2010), las regiones y las localidades se han convertido en centros estratégicos del pensamiento y las acciones del desarrollo (Storper 1995; 1998; Scott y Storper 2003). Para Amin y Thrift (1994: 155), la emergencia histórica de la economía informacional y/o del conocimiento significa, por un lado, que la globalización "está dando más importancia que antes a los factores que puedan estar agrupados bajo la etiqueta de aprendizaje, por otra parte, que hay regiones y localidades que se han transformado" en una base fundamental de la vida económica y social" (Storper 1995: 191), mediante redes que explotan los vínculos estratégicos entre la economía de "conocimiento intensivo" o informacionalismo y su input estratégico: la innovación (Hollingsworth y Boyer 1997; Florida 2000). 
En la economía informacional o basada en el conocimiento, las instituciones de educación superior son actores fundamentales del sistema de innovación, tanto como proveedores de capital humano, como creadores/promotores de nuevas ideas, iniciativas y proyectos empresariales. En esta línea, el informe The Knowledge Based Economy de la OCDE (1996) identifica como gran reto conciliar las funciones tradicionales de producción de conocimiento y la formación de científicos con el nuevo papel de colaboración con la industria en la transferencia de conocimiento y tecnología. Además, uno de los aspectos que este informe destaca es la necesidad de avanzar en propuestas que conduzcan a la plena igualdad de las mujeres en el terreno de la ciencia y la tecnología, tal y como se lleva a cabo en las actuales políticas de igualdad de las universidades.

\subsection{La transferencia de conocimiento en España y Cataluña}

En este sentido, a nivel regional, en Europa hay una tendencia creciente a fomentar estructuras de transferencia de tecnología. Estas áreas regionales de desarrollo innovador son zonas geográficas de alta concentración de actividades innovadoras. En ellas hay una elevada coordinación entre universidades, empresas y administraciones públicas, así como estructuras de intermediación como las incubadoras universitarias de empresas de base tecnológica y los parques científicos (Rodeiro et al. 2008; O'Shea et al. 2005).

En España algunas universidades ya han desarrollado estructuras para el fomento de la emprendeduría y la creación de empresas a partir de la investigación desarrollada por sus grupos de investigación, evidenciando, así, que la Universidad ya no puede limitarse a formar e investigar, las dos funciones tradicionales asignadas a las universidades, sino que se convierte en una fuente de desarrollo económico y social del territorio en que se encuentra inmersa (Hayes y Wynyard 2002; Rodríguez et al. 2005). Esta nueva Universidad se ha llamado "Universidad emprendedora" (Berman 2008; Etzkowitz 2002; 2003).

La creación de empresas y la innovación científico-técnica se está manifestando como una de las opciones que incide en la creación de empleo (Freeman y Pérez 1997), en el desarrollo económico, social y regional (Reynolds et al. 2002), en la opción de carrera por parte de la población (Rodeiro et al. 2008; 2010), en el poder de cambio social que tienen las innovaciones científico-técnicas (Moore y Frikel 2007), y en el fomento de la innovación (Acs et al. 2005), de manera que a nivel público, se han arbitrado medidas y programas de apoyo a la creación de nuevas empresas y la promoción del espíritu emprendedor (Berman 2008).

Numerosos estudios han destacado, en este sentido, el rol de las universidades como potenciales incubadoras de empresas de base tecnológica (Ussman y Postigo 2000; Vesper y Gartner 1997), además de que cada vez más la sociedad demanda un 
papel activo, no sólo en la creación de conocimiento, sino en la transferencia del mismo, de sus universidades. Así, la creación de empresas, como parte de la estrategia de transferencia de tecnología de la Universidad, se ha convertido en uno de los objetivos actuales de las autoridades académicas (Etzkowitz 2002; 2003; Etzkowitz et al. 2000; OCDE 2000; 2003; Rodeiro et al. 2008; 2010). Entre estas empresas de base tecnológica, encontramos las empresas spin-off y las empresas start-up. Una empresa spin-off universitaria es una forma particular de transferir parte del conocimiento generado en la Universidad hacia la sociedad (Clarysse, Moray y Heirman 2002; Henderson, Jaffe y Trajtenberg 1998). En ella, los investigadores actúan como emprendedores que hacen servir una gran cantidad de recursos y capacidades de la universidad en el lanzamiento de la nueva empresa. Estos recursos y/o capacidades van desde el stock de conocimiento adquirido en la investigación desarrollada en la universidad como en el desarrollo de tecnología (Rodeiro et al. 2010). En el caso español, en los últimos años la creación de spin-offs ha sido moderada. Según la Encuesta de la RedOTRI, en la primera mitad de la década se produce un aumento sostenido, con un incremento considerable entre 2005 y 2006. Dicha tendencia alcista no está exenta de controversia dentro de los propios informes de la Encuesta de la RedOTRI. Inicialmente las razones que se aducen para este aumento (especialmente para el período 2005-2006) se refieren al notable apoyo que desde las universidades se dan al emprendimiento (Informe RedOTRI 2007). Sin embargo, en posteriores ediciones se apunta a que se ha detectado una respuesta anómala de las OTRls que reportaban números "anormalmente altos y que correspondían a empresas que, promovidas desde el entorno académico y aún siendo de base tecnológica, no se basaban en resultados de investigación de la institución" (Informe de la Encuesta I+TC 2011). Unos números que se han ido corrigiendo en los años inmediatamente posteriores a 2006. En cualquier caso, a excepción de estas incidencias, podemos afirmar que, aún siendo moderada, existe una cierta tendencia alcista en la creación de spin-offs en los últimos años (Gráfico 1). 


\section{Gráfico 1. Creación de empresas spin-offs* por las universidades españolas. España. 2000-2011}

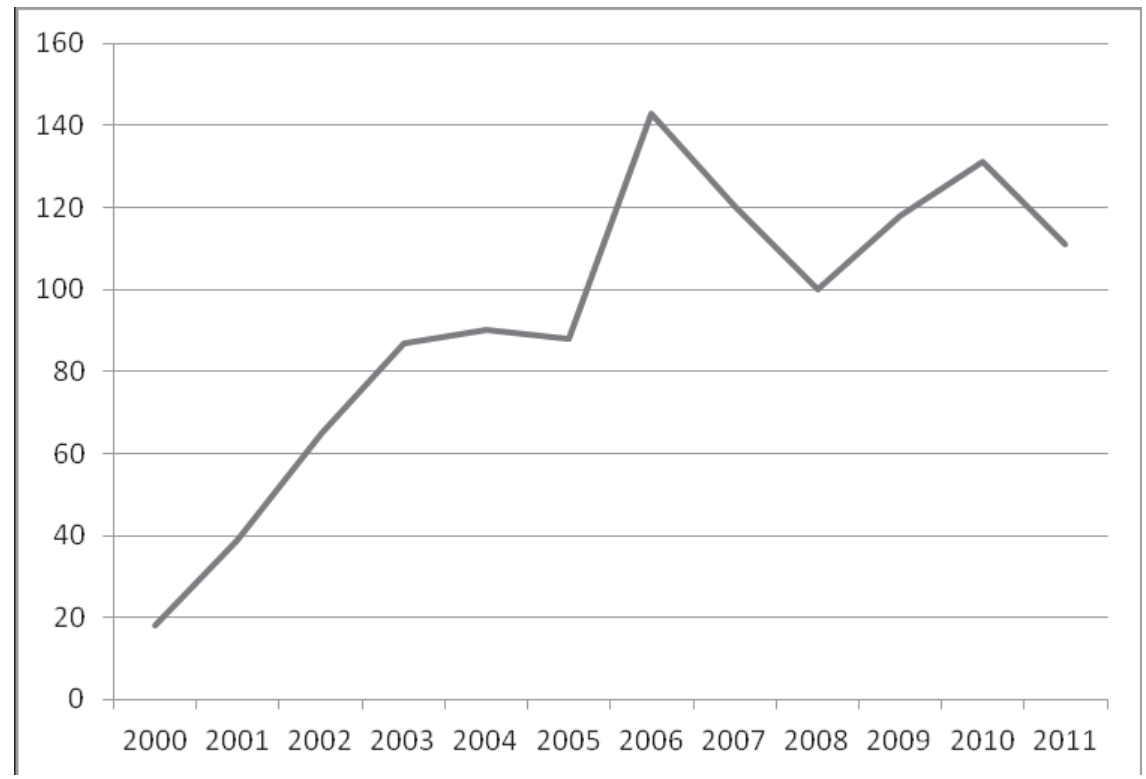

*Hasta 2006 incluye spin-off y star-up. A partir de 2007 incluye sólo spin-off. Fuente: Elaboración propia a partir de Informes encuesta RedOtri 2002-2011.

Otra cuestión es si este aumento de empresas de transferencia de conocimiento aparece vinculado con un aumento de las investigadoras que deciden ser emprendedoras. Según datos de la Estadística sobre actividades de I+D del INE, en los últimos diez años el sector de empresas ha sido el sector donde más ha aumentado el porcentaje de mujeres investigadores a jornada completa (por encima del sector de Administración pública y el de Educación superior). Aunque los datos disponibles no permiten diferenciar entre las mujeres investigadores asalariadas y las mujeres investigadoras que inician un negocio del tipo aquí planteado.

\subsection{Género y creación de empresas}

Respecto al estudio de la emprendeduría en clave de género, Parker (2004) indica que la actividad empresarial femenina no ha disfrutado del esfuerzo investigador que merece, al ser los hombres los que tradicionalmente ejercen esta actividad, de modo que la mayor parte de la investigación se ha centrado en su experiencia (Berg 1997). Sin embargo, a nivel internacional, hay un creciente número de investigaciones relativas a las mujeres emprendedoras que se evidencia en el aumento de foros de expertos internacionales (OCDE 1997; 2001; 2003). Recientemente, las investiga- 
ciones tienden a dar relevancia a la variable género para explicar la creación y el éxito de las empresas (Álvarez y Meyer 1998; Shaw, Carter y Brierton 2001; Verheul y Thurik 2001; Shinnar et al. 2012), resaltando así el importante papel que tienen las mujeres en el desarrollo de las Pymes y en la creación de empleo (Arenius y Minniti 2003; Guerrero y Urbano, 2012; GEM 2009; 2011).

En cualquier caso, si observamos la evolución de la Tasa de actividad emprendedora (TEA) ${ }^{1}$ por género, podemos confirmar la diferencia constante entre emprendedores y emprendedoras. El Gráfico 2 nos muestra como laTEA masculina, año tras año, es superior a la TEA femenina. La diferencia media en este periodo es de un $3,27 \%$ en favor de los hombres emprendedores. Durante este período, estas diferencias han oscilado desde un mínimo de un 1,7\% en el año 2001 hasta un máximo de un $5,4 \%$ el año 2003. En el año 2010 la diferencia entre la TEA masculina y la TEA femenina es de un $2,2 \%$. Por lo que tampoco podemos hablar de un aumento, al menos en términos generales, de la emprendeduría femenina.

\section{Gráfico 2:. Evolución de la TEA según género. España. 2000-2010}

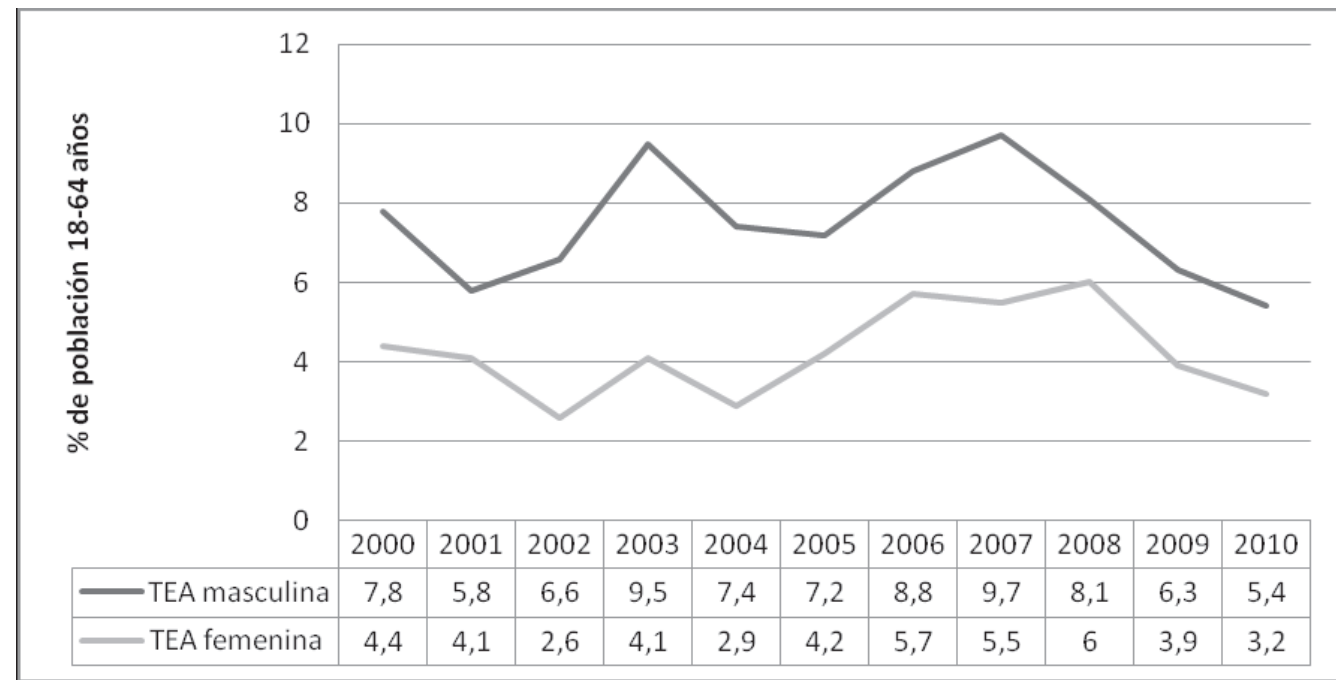

Fuente: Informe Ejecutivo GEM España 2010.

\subsection{Creación de empresas, trabajo productivo y reproductivo}

Este aumento de investigaciones sobre la actividad emprendedora femenina ha permitido definir las empresas dirigidas de mujeres en contraposición a las empresas dirigidas por sus homólogos masculinas. En este sentido, las empresas dirigidas 
por mujeres se caracterizan en relación a las de los hombres por factores como baja capitalización, baja rentabilidad, concentración sectorial y estereotipos negativos, como falta de credibilidad o menos ambición de sus metas estratégicas (Chinchilla 1997; Rosa y Hamilton 1994; Shaw, Carter y Brierton 2001). La explicación de estas características o situación de desventaja de las mujeres en la adquisición de recursos, los cuales son necesarios para crear y dirigir un negocio con éxito, se encuentra, teniendo en cuenta la distribución desigual de recursos, en diferentes factores. Entre ellos, la necesidad de buscar fórmulas alternativas de conciliación de la vida laboral y familiar conduce a las mujeres a tener una mayor propensión hacia el autoempleo que los hombres (Baines, Wheelock y Gelder 2003; Gardiner 1997; Williams 2004). Sin embargo, las motivaciones para el autoempleo de hombres y mujeres son diferentes en tanto que su situación de partida respecto a la relación entre trabajo productivo y reproductivo es diferente, porque aunque las mujeres se están incorporando progresivamente al mercado de trabajo, como contrapartida, los hombres no se incorporan al mismo ritmo al reparto del trabajo doméstico (Boden 1999; Connely 1992). EI GEM (2008), en España, apunta que la ausencia de unos sistemas de conciliación de la vida familiar y laboral efectivos constituye una de las principales trabas de las emprendedoras ante sus homólogos masculinos.

Por otra parte, las investigaciones internacionales sugieren que hay una correlación positiva entre el número de hijos y la probabilidad de creación de empresas por parte de mujeres, especialmente durante la infancia de los hijos (Boden 1999; Connely 1992; Greenhaus y Parasuraman 1999). Algunas investigaciones, a partir de este resultado, han inferido que la opción del autoempleo está positivamente relacionada con el trabajo doméstico, derivado de las cargas familiares (Boden 1999; Shelton 2006; Baines y Weelock 2000). El autoempleo se valora positivamente por su flexibilidad en la cantidad, el tiempo y el lugar de trabajo (Hildebrant y Williams 2003); flexibilidad que, supuestamente, permite una mayor conciliación entre vida laboral y familiar. Sin embargo, pese a que la conciliación entre vida laboral y familiar puede ser una motivación para el autoempleo, otras investigaciones muestran cómo esta estrategia puede tener efectos no deseados, reduciendo, finalmente el tiempo total destinado al cuidado de los hijos (Baines te al. 2003).

En una investigación realizada a partir del panel de hogares de la Unión Europea con datos relativos a ocho países, Williams (2004) indica que tanto en el caso de hombres como de mujeres la principal variable explicativa de la perdurabilidad en la situación de ocupados/as por cuenta propia es la cantidad de tiempo dedicado a esta actividad remunerada. En cuanto al cuidado de los hijos, los resultados son diferentes entre hombres y mujeres. Mientras que en el caso de los hombres el número de hijos tiene un efecto positivo sobre la permanencia en el autoempleo, en el caso de las mujeres tiene un efecto insignificante aunque de dirección negativa en el agregado de los países analizados. En cambio, cuando se observan por separado los diferentes países, se observa en el sur de Europa como el número de hijos tiene un efecto negativo sobre la duración del autoempleo, lo que nos remite, de acuerdo 
con el autor, a las diferencias de protección de los Estados de bienestar y, siguiendo a Torns (2005), a las carencias en servicios de atención a la vida diaria en España.

En este sentido, la Encuesta de Usos del Tiempo muestra como, en 2009-2010, muestran dos aspectos interesantes. El primero de ellos es que los hombres empresarios participan y dedican menos tiempo a las responsabilidades domésticas y familiares que sus homólogos asalariados (64,9\% y 77,1\%, respectivamente). Además, los primeros dedican, de media diaria, 20 minutos menos que los segundos. En cambio, no se ven tantas diferencias si hablamos de mujeres empresarias o trabajadoras. Su dedicación prácticamente es la misma (92,1\% y 93,5\%, respectivamente) y su inversión en tiempo se diferencia en solo 10 minutos. Por tanto, no parece que la dedicación por parte de las mujeres a la dirección y gestión de empresas suponga, en términos generales, una menor dedicación al cuidado de su hogar y de sus hijos.

\section{TABLA 1. Personas que realizan la actividad en el día y duración media diaria*. España. 2009-2010}

\begin{tabular}{|c|c|c|c|c|}
\hline \multirow[b]{2}{*}{ España (2009 -2010) } & \multicolumn{2}{|c|}{ Hombres } & \multicolumn{2}{|c|}{ Mujeres } \\
\hline & $\begin{array}{c}\% \text { de } \\
\text { personas }\end{array}$ & $\begin{array}{c}\text { Duración } \\
\text { media }\end{array}$ & $\begin{array}{c}\% \text { de } \\
\text { personas }\end{array}$ & $\begin{array}{c}\text { Duración } \\
\text { media }\end{array}$ \\
\hline \multicolumn{5}{|l|}{ Hogar y familia (datos generales) } \\
\hline Empleador/a o Empresario/a sin asalariado/as & 64,9 & 2:05 & 92,1 & $3: 55$ \\
\hline Asalariados/as & 77,1 & $2: 25$ & 93,5 & $3: 45$ \\
\hline \multicolumn{5}{|l|}{ Cuidado de niños } \\
\hline Empleador/a o Empresario/a sin asalariado/as & 22,1 & $1: 25$ & 32,8 & $1: 47$ \\
\hline Asalariados/as & 26,6 & $1: 42$ & 32,1 & $2: 08$ \\
\hline \multicolumn{5}{|l|}{ Mantenimiento del hogar } \\
\hline Empleador/a o Empresario/a sin asalariado/as & 21,6 & $0: 54$ & 54,4 & $1: 05$ \\
\hline Asalariados/as & 30,8 & $0: 49$ & 62,2 & $1: 07$ \\
\hline \multicolumn{5}{|l|}{ Trabajo remunerado (datos generales) } \\
\hline Empleador/a o Empresario/a sin asalariado/as & 79,6 & $8: 39$ & 78,6 & 7:01 \\
\hline Asalariados/as & 68,5 & $8: 13$ & 67,7 & $6: 54$ \\
\hline
\end{tabular}

* Resultados detallados en función de actividades y situación profesional. Fuente: Elaboración propia a partir del INE. Encuesta de Usos del Tiempo.

Observamos, pues, que aunque las motivaciones para el autoempleo pueden ser elevadas, existen restricciones de orden institucional relevantes, ya que las instituciones definen lo que los actores pueden hacer, qué se espera de ellos, que han de hacer y que resultaría más ventajoso para ellos. Estas restricciones tienen que ver 
con el género de las empresarias (Ferguson y Durup 1997), ya que las mujeres que eligen crear un negocio no están exentas de tener un doble papel como empresarias y "amas de casa» (Brush et al. 2004).

\section{Estrategia metodológica}

Para conseguir estos objetivos la investigación se ha desarrollado en tres fases, con un diseño que combina el uso de técnicas cuantitativas y cualitativas. La utilización de las diferentes técnicas está en consonancia con las fases de las que consta la investigación.

$1^{\text {a }}$ fase: Para la primera fase se ha realizado una selección de mujeres investigadoras con una trayectoria profesional reconocida (la totalidad de las entrevistadas son directoras de grupos de investigación consolidados), distribuidas entre las diferentes universidades públicas catalanas, a las que se les ha hecho una serie de entrevistas semi-estructuradas de tipo exploratorio. El objetivo era el de obtener un mayor conocimiento de las estructuras y procesos vinculados a la creación de spinoffs y donde destaca el ámbito de la investigación y de la universidad. También se pretendía obtener un mayor conocimiento de la dimensión de género y sus características dentro de un ámbito tan complejo como el de la investigación universitaria. Se han realizado una totalidad de 10 entrevistas distribuidas entre 7 universidades catalanas. El guión pretendía profundizar en aspectos tales como las características de los grupos de investigación y su relación con la transferencia de conocimiento, las trayectorias de mujeres investigadoras y la relación entre investigación y trabajo reproductivo. En el análisis las entrevistas aparecen codificadas con el acrónimo EMD (Entrevista a Mujer Directora) seguido de una numeración.

$2^{\text {a }}$ fase: Para la segunda fase se ha realizado una encuesta a todas las empresas spin-off universitarias de Cataluña. El universo para la realización de la encuesta ha estado formado por todas las empresas spin-off creadas por las universidades catalanas y activas en julio de 2011, vinculadas a los sectores con más nivel tecnológico (quedan excluidos, pues, los sectores de sociales y humanidades). La encuesta a través de cuestionario se ha hecho bajo la modalidad de cuestionario vía mail, dada la dispersión territorial de las empresas a entrevistar. La encuesta ha sido dirigida al universo completo de empresas spin-off generadas por las universidades. Por tanto, no ha habido estrictamente una selección muestral sino que el objetivo ha sido el de abarcar el mayor número posible de empresas que forman el universo poblacional de spin-offs. El universo poblacional de las empresas spin-off universitarias catalanas es de 103 casos con un nivel de respuesta de casi el 40 por ciento. El cuestionario recoge datos agrupados en los siguientes apartados: características de la empresa, datos sociodemográficos del emprendedor/a, trayectoria laboral y profesional, red de relaciones sociales en la creación de la spin-off, mercado y estrategias competitivas, conciliación de la vida laboral y familiar. A partir de los datos recogidos por 
la encuesta se ha podido realizar un análisis de los datos con un doble objetivo. En primer lugar, analizar las características generales de las empresas spin-off, a partir de diferentes elementos recogidos en el cuestionario (características de la empresa, mercado y estrategias competitivas). En segundo lugar, analizar el perfil de los emprendedores y emprendedoras de estas empresas, atendiendo a sus diferencias en función de la dimensión de género (datos sociodemográficos del emprendedor/a, trayectoria laboral y profesional, red de relaciones sociales en la creación de la spinoff, conciliación de la vida laboral y familiar).

$3^{a}$ fase: Para la tercera y última fase, se ha hecho una selección de emprendedores y emprendedoras del total de empresas encuestadas, a los que se les ha hecho una serie de entrevistas en profundidad. En el análisis las entrevistas aparecen codificadas con el acrónimo EME (Entrevista a Mujer Emprendedora) y el acrónimo de EHE (Entrevista a Hombre Emprendedor) seguido de una numeración. Se ha realizado un total de 11 entrevistas, fundamentalmente a mujeres emprendedoras con el objetivo de entrevistar al máximo de mujeres emprendedoras (verTabla 2). El guión de las entrevistas recoge aspectos tales como las características de la spin-off (poniendo especial énfasis en las motivaciones iniciales, el momento de la creación de la empresa, la identificación de dificultades, los apoyos recibidos, etc.), el papel de las administraciones públicas (así como el de la universidad), las trayectorias personales de los hombres y mujeres emprendedores y la relación entre trabajo productivo y reproductivo. El objetivo de esta fase ha sido el de profundizar en las hipótesis de partida de esta investigación y que tienen que ver con el impacto de la división sexual del trabajo en la desigual presencia de hombres y mujeres en la generación de estas empresas, focalizando la atención en las percepciones que de esta relación tienen los hombres y mujeres responsables de empresas spin-off. Lo que se ha buscado en esta fase ha sido llegar a tener un cierto conocimiento de las trayectorias formativas y laborales de los hombres y mujeres fundadores de empresas spin-off, conocimiento que a nuestro juicio puede ayudar a comprender mejor la relación entre la división sexual del trabajo y la creación de de este tipo de iniciativas de negocio.

El análisis cualitativo ha combinado los datos recogidos en las fases 1 y 3 , teniendo en cuenta la complementariedad de los guiones de las entrevistas realizadas. El análisis cuantitativo se ha centrado en la explotación de los datos recogidos mediante la encuesta realizada en la segunda fase.

\section{Spin-offs universitarias y género: análisis de datos}

Tal y como se apunta en el apartado metodológico, los datos obtenidos con la encuesta se han visto complementadas con una serie de entrevistas semi-estructuradas a mujeres directoras de grupos de investigación y entrevistas en profundidad a hombres y mujeres emprendedores. El análisis aquí expuesto combina estos datos 
obtenidos con el objetivo de conseguir un hilo conductor coherente que nos permita responder a nuestra hipótesis.

\subsection{Investigación y empresas: la desigual presencia de la mujer}

El primer elemento a tener en cuenta de las entrevistas realizadas es la percepción de la limitada presencia de mujeres al frente de empresas de transferencia de conocimiento. Aunque algunos entrevistados y entrevistadas perciben un cierto aumento de mujeres emprendedoras en este sector, la presencia de hombres como responsables de empresas spin-off sigue siendo plenamente mayoritaria (EME2, EME8, EME10, EHE1).

De las entrevistas no se derivan elementos que nos hagan pensar que parte de esta menor presencia viene condicionada por las limitaciones o dificultades hacia las mujeres emprendedoras a la hora de crear una empresa. No se observa que las instituciones encargadas de gestionar y asesorar este tipo de iniciativas tengan algún tipo de incidencia. Otra cuestión es el carácter mayoritariamente masculino de las propias estructuras universitarias, en referencia a los grupos de investigación, departamentos y otros.

Los resultados de la encuesta realizada a la totalidad de empresas spin-off en Cataluña vienen a confirmar esta percepción mayoritaria. La proporción de empresas en donde uno de los responsables o corresponsables es una mujer, resulta muy bajo. Según laTabla 2, una de cada diez empresas spin-off está dirigida por una mujer (10,7\%). Estas diferencias son más acusadas que los datos sobre dirección de empresas entre hombres y mujeres a nivel general. Según la EPA, en el $4^{\circ}$ trimestre de 2010 y para Cataluña, el $28,7 \%$ de los empresarios eran mujeres frente al 71,3\% de los hombres.

TABLA 2. Empresas spin-off según género en Cataluña

\begin{tabular}{|l|c|c|}
\hline & Absolutos & Porcentajes \\
\hline Empresas dirigidas por hombres & 92 & 89,3 \\
Empresas dirigidas por mujeres & 11 & 10,7 \\
Total empresas & 103 & 100 \\
\hline
\end{tabular}

Fuente: Elaboración propia.

La presencia de mujeres empleadas en las empresas estudiadas (Gráfico 3) también resulta relativamente baja. La proporción de mujeres empleadas en empresas spin-off es de un $29,8 \%$ de media. En cambio, la presencia de mujeres empleadas 
varía significativamente si diferenciamos entre empresas dirigidas por hombres y mujeres. La media de mujeres empleadas para empresas dirigidas por hombres es de un $25,2 \%$, mientras que para empresas dirigidas por mujeres, la presencia de estas aumenta hasta un $55,2 \%$ de media.

\section{GráfICo 3. Proporción de mujeres empleadas en spin-offs}

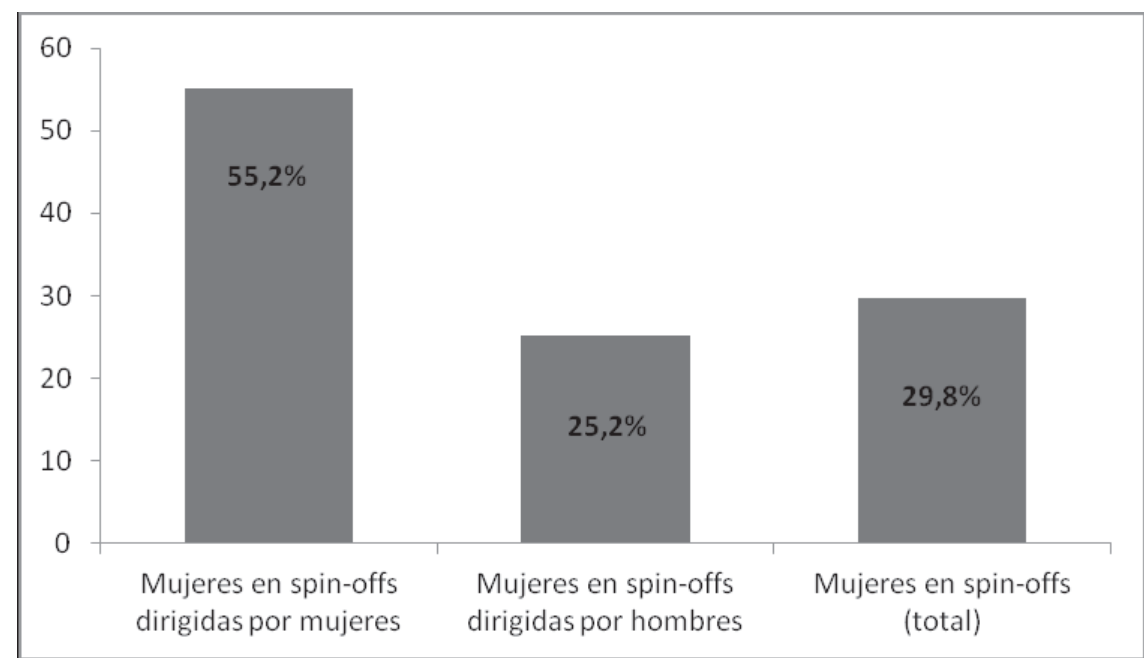

Fuente: Elaboración propia.

Cuando se pide a las entrevistadas por la trayectoria académica y/o de investigación, el primer elemento a tener en cuenta es la desigual presencia que existe entre hombres y mujeres actualmente en el ámbito de la investigación. Cierto es que los niveles de presencia de investigadoras femeninas ha aumentado en la última década. Pero, aún así, seguimos estando ante un mundo preferentemente masculino. Hoy, la presencia de mujeres que optan por estudiar una carrera universitaria ha aumentado considerablemente, hasta el punto que en algunos estudios la presencia de hombres resulta residual. Pero llega un momento donde esta mayor presencia de mujeres que de hombres se revierte en favor de estos últimos. El momento de realizar estancias postdoctorales en el extranjero resulta el punto de inflexión en el cambio de presencia entre hombres y mujeres en el ámbito de la investigación (EMD1, EMD3, EMD5, EMD8, EMD9, EMD11).

Las razones que hay detrás de este cambio son diversas en función de la persona entrevistada. En este sentido, encontramos dos modelos de discursos claramente diferenciados. Un modelo de discurso más tradicional y más neutro al género, donde los factores que condicionan la trayectoria académica e investigadora de una persona son estrictamente científicos. En el otro modelo de discurso, más sensible 
al género, son las cargas familiares y las expectativas que la sociedad tiene sobre las mujeres y su "obligada" responsabilidad hacia estas cargas las que condicionan en gran medida la desigual trayectoria académica e investigadora de hombres y mujeres (EMD1, EMD2, EMD3, EMD4, EMD9, EMD11).

\subsection{División sexual del trabajo}

La relación entre trabajo productivo y trabajo reproductivo aparece presente en todos los discursos de las emprendedoras entrevistadas con hijos. Relación que, en cambio, no tiene la misma presencia en los discursos de los emprendedores con hijos. En ellos, parece no haber una conexión entre ambas dimensiones. Familia y trabajo no parecen interferir entre sí. La razón, en parte, es el resultado de la plena asunción de las responsabilidades familiares por la propia pareja, llegando a la interiorización de un discurso por parte de los hombres emprendedores, en donde ambas esferas no parecen estar relacionadas. O, dicho de otra forma, un discurso donde no parece que ambas esferas se condicionen entre sí. A pesar de que este discurso es mayoritario, aparecen algunos elementos en algunos discursos de emprendedores que reconocen la importancia de la asunción de estas responsabilidades por parte de la propia pareja, para que uno mismo pueda desarrollar con éxito su trabajo (EHE2, EHE3, EHE4, EHE5).

Lo contrario ocurre con los discursos de las mujeres emprendedoras entrevistadas. La familia y la relación de este ámbito con el ámbito profesional es una constante en todos los discursos analizados. Esta presencia del ámbito familiar en el discurso de las mujeres emprendedoras condiciona el día a día de su trabajo como responsables de sus empresas y supone un agravio comparativo hacia sus homólogos masculinos. De las entrevistas no se derivan elementos que indiquen mayores o menores dificultades para conciliar vida laboral y familiar en función de si hablamos de trabajo por cuenta propia o trabajo por cuenta ajena. Parecen más decisivos factores como el apoyo familiar y la organización de las responsabilidades familiares con la propia pareja, cuestión que se tratará más adelante (EME2, EME4, EME5).

En esta línea, unos de los elementos importantes dentro de la encuesta es el apartado que hace referencia al nivel de dedicación al trabajo reproductivo, o si se quiere, las cargas domésticas y familiares que llevan a cabo los emprendedores y emprendedoras. Podemos observar diferencias significativas respecto a la asunción de estas responsabilidades en función de si hablamos de hombres y mujeres. Si estudiamos las respuestas sólo para los casos con hijos, estas diferencias se acentúan. Según el Gráfico 4, el nivel de dedicación de las tres dimensiones principales de las tareas familiares (a saber: mantenimiento y cuidado del hogar, cuidado y atención de hijos y personas mayores, y organización y gestión del hogar) es significativamente superior en el caso de las mujeres emprendedoras que en el caso de los hombres. Así, mientras que 7 de cada 10 mujeres realizan la mitad o más del volu- 
men de trabajo derivado de estas tareas (75\%), los hombres se quedan en un $19 \%$. Si solo consideramos aquellos emprendedores y emprendedoras que tienen hijos (Gráfico 4), las diferencias aumentan considerablemente. Tanto hombres como mujeres dedican menos tiempo al conjunto de responsabilidades domésticas y familiares. El $66,7 \%$ de las mujeres dedican la mitad o más de su tiempo, mientras que sólo el 5,9\% de los hombres dedican estos tiempos. Las mujeres bajan en 11 puntos (de $75 \%$ a $66,7 \%$ ), mientras que los hombres bajan 13,1 puntos (de $19 \%$ a $5,9 \%$ ). Los resultados son similares si los desagregamos por tipo de tareas familiares. Así, tanto en el mantenimiento del hogar como en el cuidado y atención de hijos, las mujeres superan en nivel de dedicación a los hombres. Estas diferencias aumentan para las tareas de cuidado y atención de hijos.

\section{GRÁfICO 4. Responsabilidad del encuestado/a (todas las cargas familiares)}

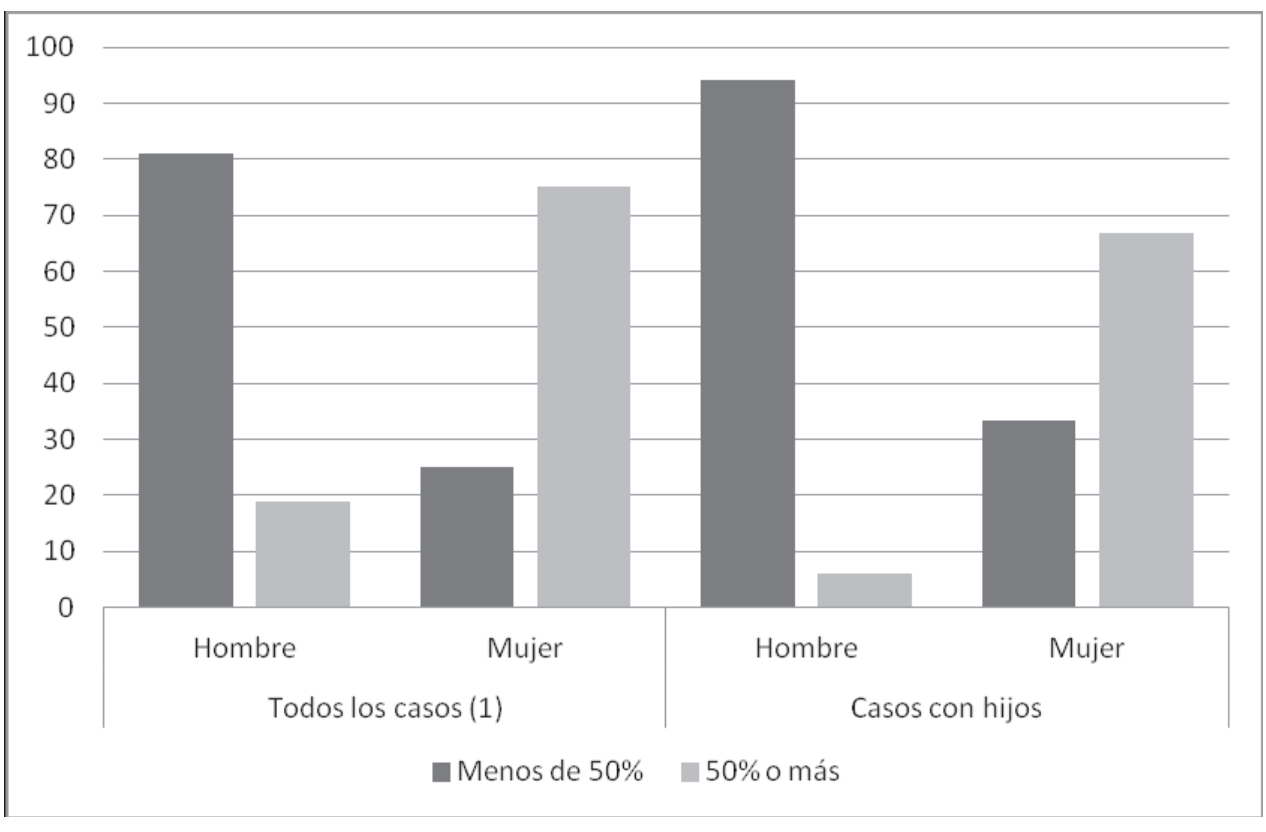

(1) Se incluyen casos con hijos y casos sin hijos.

Fuente: Elaboración propia.

La dimensión en donde encontramos más diferencias es la dimensión del cuidado y atención de los hijos (Gráfico 5). Aquí, la diferencia entre hombres y mujeres emprendedores es muy acusada. Como podemos observar, la totalidad de las mujeres emprendedoras se dedican mayoritariamente al cuidado y atención de sus hijos, mientras que sólo el $11,8 \%$ de los hombres emprendedores se dedican en porcentaje igual o superior al cincuenta por ciento. El cuidado de hijos sigue siendo la tarea 
y/o responsabilidad de las mujeres, independientemente de la situación profesional de las mismas, así como de la situación profesional de sus parejas. Una tarea que resulta la más rígida y compleja y que necesita de más dedicación temporal que el resto de tareas vinculadas al hogar y la familia (según la Encuesta de Usos delTiempo 2009-2010 del INE, la actividad que conlleva una mayor dedicación en la dimensión de Hogar y Familia es la de Cuidado de hijos con una media diaria de 2 horas y 7 minutos).

\section{GrÁfICO 5. Responsabilidad del encuestado/a en cuidado de hijos (porcentajes)}

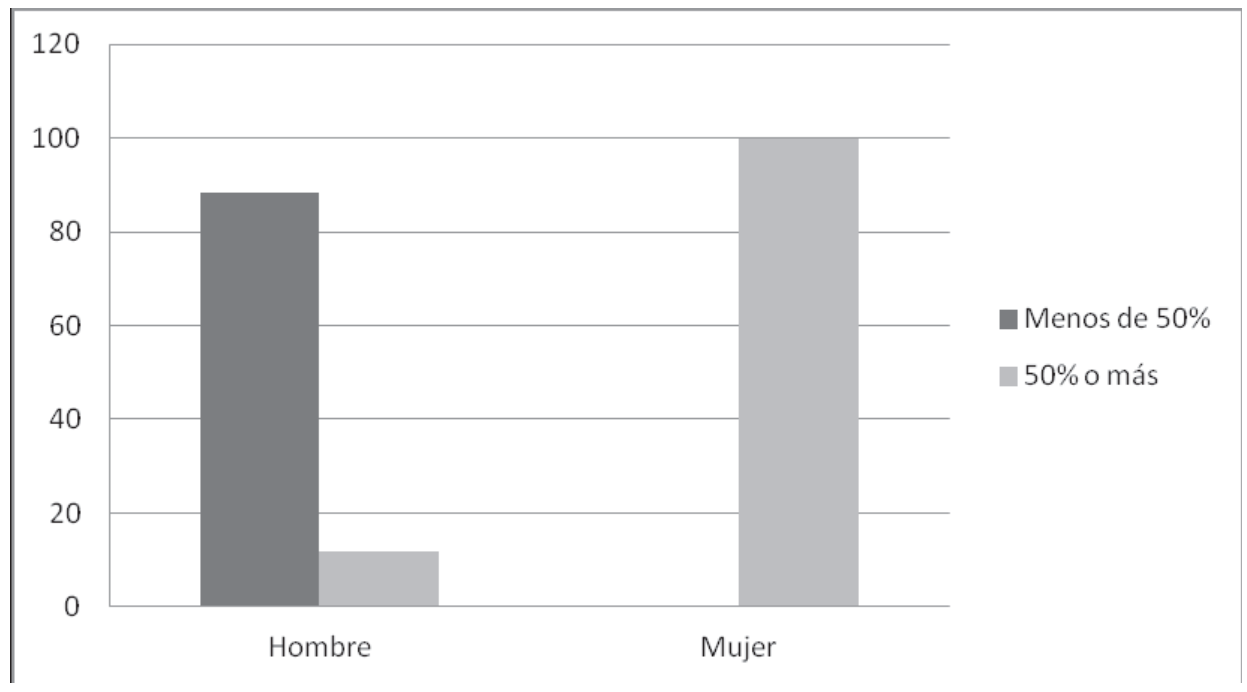

Fuente: Elaboración propia.

Este desigual reparto respecto a las tareas domésticas y familiares se evidencia también cuando se pide por posibles consecuencias negativas de la maternidad o paternidad sobre la trayectoria profesional (Gráfico 6). Mientras que casi 7 de cada 10 mujeres consideran que la maternidad no las ha perjudicado, la totalidad de los hombres emprendedores manifiestan que la paternidad no ha supuesto ningún perjuicio en su trayectoria profesional. 


\section{GRÁfICO 6. Perjuicios maternidad/paternidad sobre trayectoria profesional}

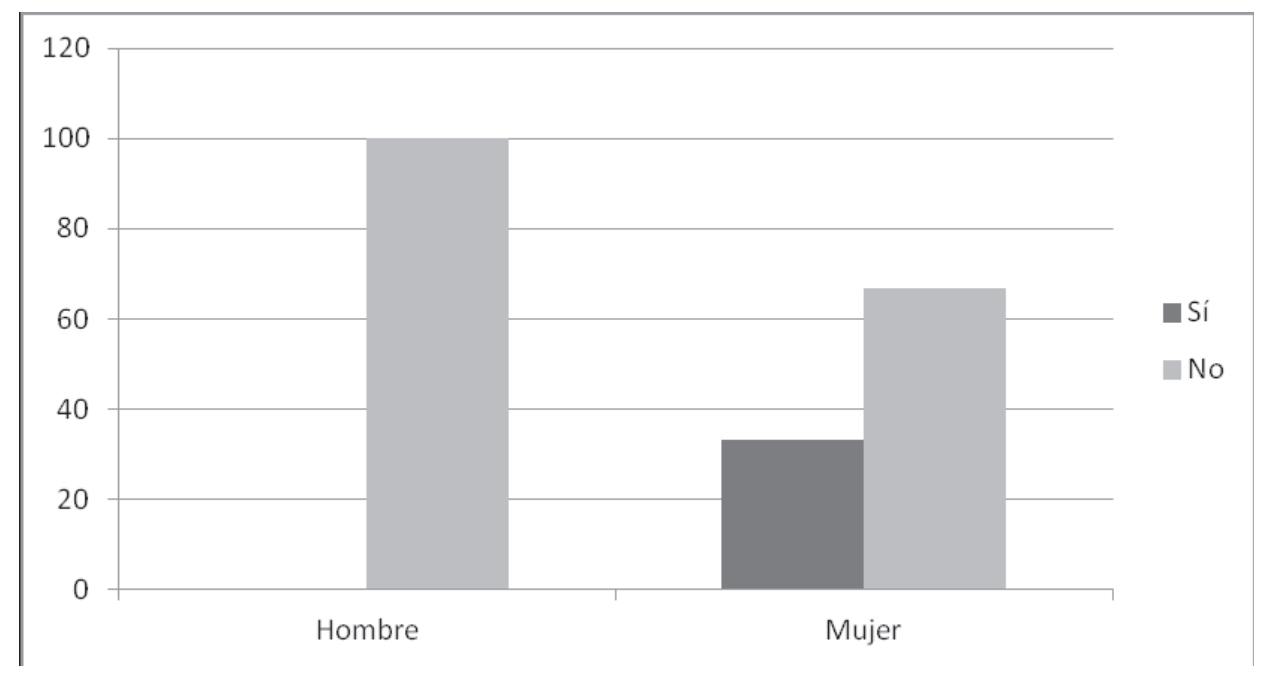

Solo casos con hijos.

Fuente: Elaboración propia.

\subsection{Capital social y familiar: el factor "pareja" o la importancia del apoyo familiar}

Como ya se ha apuntado, uno de los elementos que aparecen en las entrevistas realizadas es la importancia del apoyo familiar, fundamentalmente de la propia pareja, a la hora de iniciar y mantener una iniciativa empresarial de este tipo. Este apoyo se materializa de dos formas diferentes, en función de si hablamos de emprendedores o emprendedoras. Por un lado, respecto a los hombres emprendedores, este apoyo se materializa en la derivación mayoritaria de las responsabilidades familiares en la propia pareja. En cambio, respecto a las mujeres emprendedoras, este apoyo se traduce en la asunción de responsabilidades familiares en términos paritarios (corresponsabilidad del cuidado). A estos apoyos diferenciados hay que añadir un apoyo emocional y afectivo hacia la iniciativa que pone en marcha tanto el emprendedor como la emprendedora (EHE1, EHE2, EHE3, EHE5, EME2, EME5).

Los resultados de la encuesta siguen esta misma línea argumental. Respecto a la pregunta sobre la valoración que hacen los emprendedores y emprendedoras del apoyo recibido por parte del entorno familiar (pareja, padres y parientes) y el entorno amical y laboral (amigos y colegas de trabajo) (Gráfico 7), los resultados en términos generales son muy positivos. El $70,4 \%$ de los hombres y mujeres emprendedores han manifestado que tanto la familia como el entorno amical y laboral les han animado en el momento de poner en marcha su negocio. Los porcentajes se mantienen relativamente si diferenciamos según hombres y mujeres, aunque las muje- 
res emprendedoras se ven un poco más apoyadas por su entorno. El $71,4 \%$ de las mujeres emprendedoras manifiestan que este entorno las animó en el momento de poner en marcha su negocio, frente al $64 \%$ de los hombres emprendedores.

\section{GRÁfICo 7. Apoyo inicial general según género (porcentaje de respuestas)}

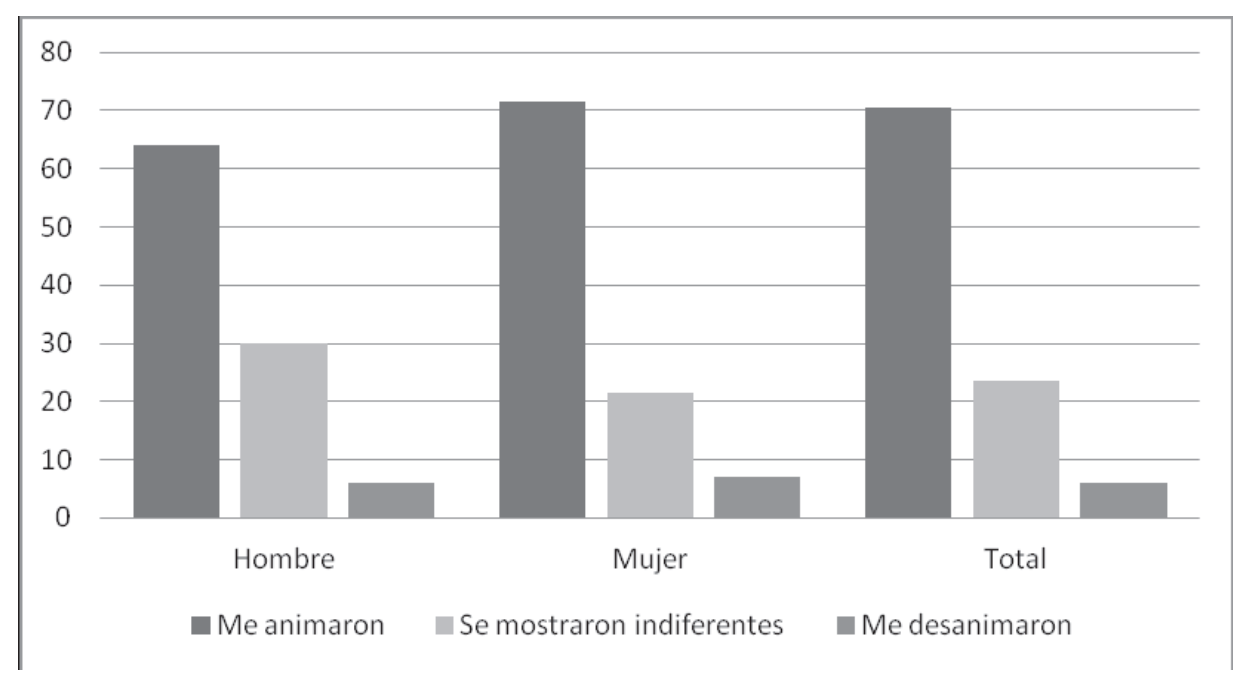

Fuente: Elaboración propia.

Estas diferencias, en cambio, varían en función del entorno de apoyo inicial. Así, tal y como podemos ver en el Gráfico 8, las mujeres emprendedoras encuestadas muestran un apoyo inicial por parte del entorno familiar mayor que sus homólogos masculinos. Tanto si se trata de la pareja como si se trata de los padres, la totalidad de las mujeres emprendedoras manifiestan que estos las animaron en el momento de poner en marcha su empresa. En el caso de los hombres emprendedores, los porcentajes bajan hasta un $88,5 \%$ para el apoyo de la propia pareja y hasta un $65,5 \%$ para el apoyo de los padres. Respecto al apoyo por parte de los parientes o familiares más cercanos, las mujeres también tienen un mayor apoyo que los hombres. Un $75 \%$ de las mujeres manifiestan que las animaron frente a un $57,1 \%$ de los hombres. Estos datos pueden tener dos lecturas. La primera y más manifiesta es que las mujeres emprendedoras tienen un mayor apoyo por parte de su entorno familiar que los hombres emprendedores. La segunda lectura sería que aquellas mujeres emprendedoras que ponen en marcha una iniciativa de este tipo necesitan de un mayor apoyo que sus homólogos masculinos. O dicho de otra forma, los hombres emprendedores no necesitan un apoyo tan importante para poder poner en marcha su negocio. 
GrÁfICo 8. Apoyo inicial por pareja, padres y parientes según género (porcentajes)

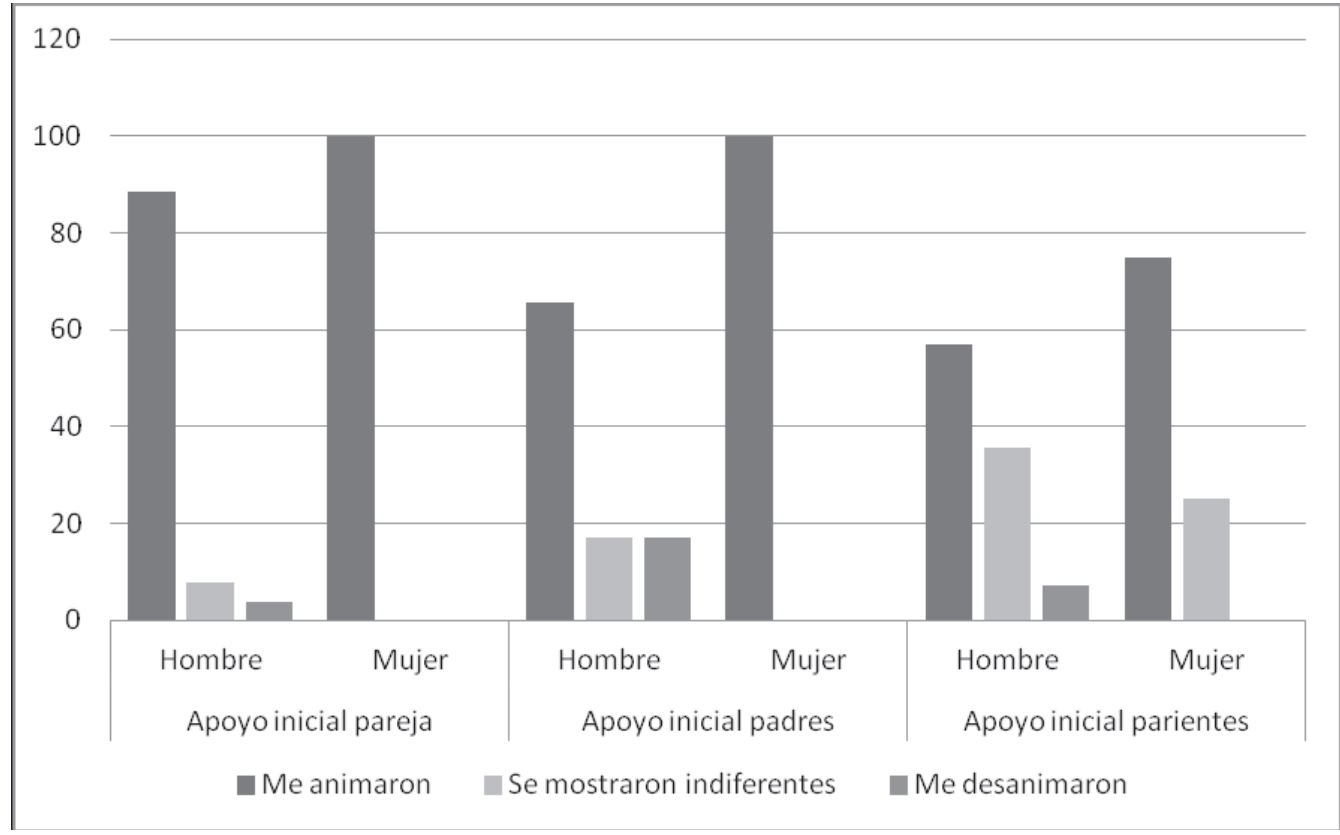

Fuente: Elaboración propia.

Respecto al apoyo recibido por parte de amigos y colegas de trabajo (Gráfico 9), la tendencia se invierte. Ahora, son los hombres emprendedores los que manifiestan un mayor apoyo por parte de los amigos y por parte de su entorno laboral. EI $80 \%$ de los hombres manifiestan que sus amigos les animaron en el momento de poner en marcha su empresa, frente al $50 \%$ de sus homólogas femeninas. Respecto al entorno laboral, el $76,7 \%$ de los hombres manifiestan que sus colegas de trabajo les animaron frente al $40 \%$ de las mujeres emprendedoras. 


\section{Gráfico 9. Apoyo inicial por amigos y colegas de trabajo según género (porcentajes)}

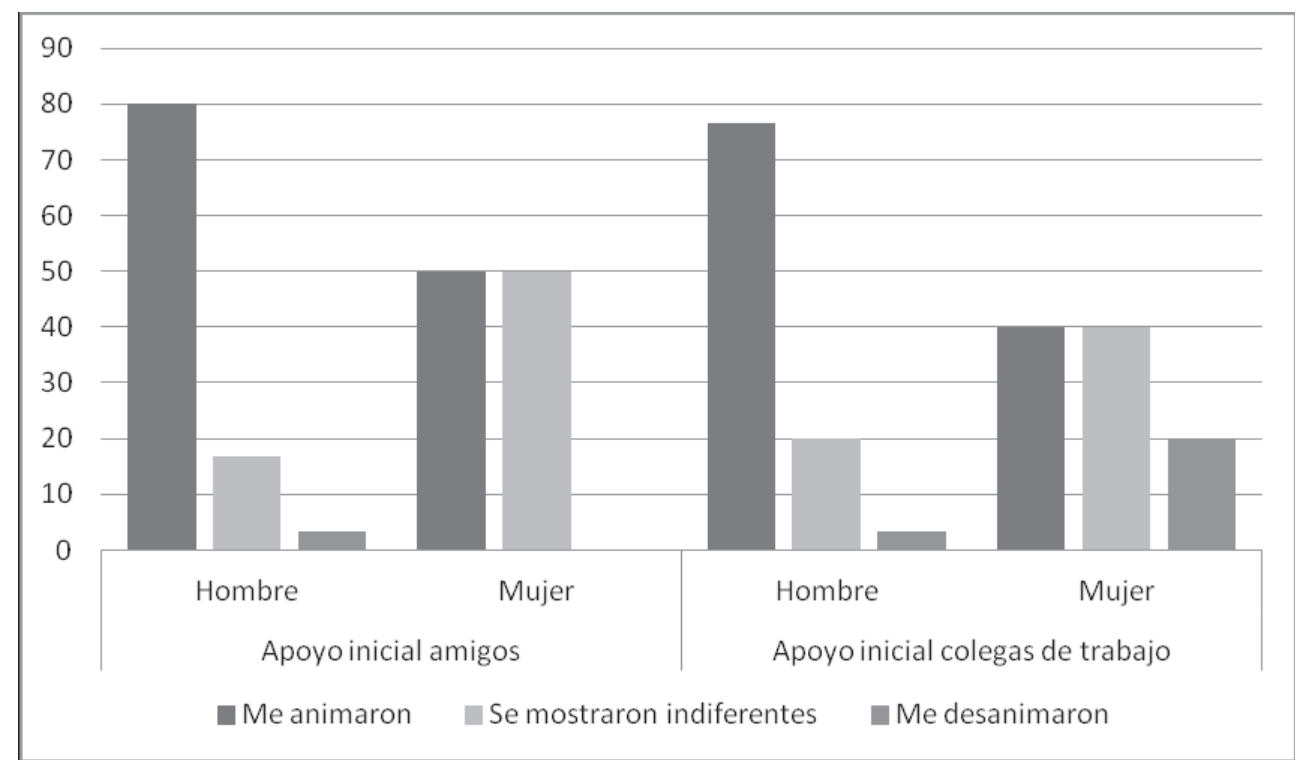

Fuente: Elaboración propia.

\subsection{Estrategias diferenciadas por género}

Esta fuerte presencia de las cargas familiares o, si se quiere, del trabajo reproductivo sobre la esfera pública o visible del ámbito profesional, condiciona en gran medida la propia forma de concebir la vida de hombres y mujeres y de su relación con respecto a diferentes dimensiones (como el trabajo, la familia, etc.). Es tal esta incidencia que el discurso acaba interiorizado. Este discurso se observa a partir de los estereotipos masculinos y femeninos que manifiestan las investigadoras entrevistadas. Los hombres aparecen como individuos más competitivos, asumen más riesgos y tienen más claros sus objetivos. Las mujeres, en cambio, serían menos competitivas y buscan más la seguridad y la estabilidad de un trabajo por encima de los riesgos que, a veces, supone la carrera investigadora (EMD4, EMD5, EMD6, EMD7, EMD9).

Este discurso resulta interesante si vinculamos la idea del emprendeduría como forma de entender el trabajo más asociada a riesgos y novedades que a una cierta estabilidad, más si hablamos del momento inicial de la creación de una empresa. En este sentido, cabría pensar que los hombres, además de tener menos obstáculos en la carrera académica e investigadora, también estarían más predispuestos a poder 
iniciar un proceso de creación de una empresa. Pero, como ya se ha apunta antes, de las entrevistas se desprende que esta búsqueda de estabilidad y de seguridad por parte de las mujeres está condicionada por su asunción de un ámbito, el familiar, que debe ser necesariamente compatible con su ocupación (si es que quieren continuar desarrollando este ámbito profesional). Los hombres, en cambio, no suelen tener en cuenta ambos ámbitos a la hora de tomar decisiones sobre su trayectoria profesional. Dicho de otra forma, las mujeres ponen en la misma balanza familia y empleo y buscan la forma de hacerlos compatibles. Y estas decisiones vienen condicionadas por diversos factores, como es el apoyo familiar, materializado en el "pacto" adquirido con la pareja, las expectativas familiares propias así como las condiciones del propio empleo. Este último factor hace referencia a unas condiciones laborales (fundamentalmente referente a los horarios) que sean compatibles con sus actuales o futuras responsabilidades familiares. Los hombres, en cambio, mayoritariamente no tienen en cuenta la familia a la hora de "pensar" en su empleo, lo que permite tomar decisiones sobre éste sin condicionantes ni limitaciones (EMD9).

Esta forma diferente de encarar las dimensiones productiva y reproductiva genera diferencias entre hombres y mujeres a la hora de plantear una iniciativa como la creación de una empresa spin-off. Una iniciativa que se aleja de los parámetros del trabajo por cuenta ajena en términos de horarios, seguridad y estabilidad, entre otros. También resulta muy importante, como ya hemos mencionado, la red de apoyo, sea este familiar, representado por el apoyo de la pareja, como por parte de la universidad, representado por el grupo de investigación, el departamento y/o la facultad donde se ha formado el investigador o investigadora. No parece frecuente que desde los doctorandos y doctorandas $\mathrm{y}$, posteriormente, los investigadores e investigadoras ya doctores y doctoras, se plantee la alternativa de la emprendeduría como una opción futura posible. La falta de apoyo familiar o de corresponsabilidad en las tareas familiares dificulta en mayor medida el planteamiento de este tipo de iniciativas a las mujeres potencialmente emprendedoras que a sus homólogos masculinos (EMD1, EMD4).

Un elemento interesante que aparece en algunos de los discursos es la adopción de estrategias diferenciadas en función de si hablamos de emprendedores o emprendedoras. De algunas entrevistas se deriva que las mujeres emprendedoras adoptan o serían más propensas a adoptar estrategias que podríamos denominar más "conservadoras" a la hora de gestionar una empresa. Con estrategias más conservadoras nos referimos a la no aceptación de inversiones o socios externos, como capital riesgo o la entrada de un socio mayoritario en la empresa. Las mujeres emprendedoras quieren "controlar" su negocio de forma integral y la entrada de capital riesgo podría suponer una pérdida de control del mismo y, según las entrevistadas, una mayor dedicación a la empresa. La razón de esta mayor voluntad de control de su empresa viene condicionada, una vez más, por la búsqueda constante de compatibilidad entre su vida profesional y su vida familiar. Para algunas entre- 
vistadas, la entrada de inversiones externas del tipo de sociedades de capital riesgo o socios mayoritarios, supondría una presión externa al alza que derivaría en el sacrificio de una de las dos "vidas" en favor de la otra. Las mujeres emprendedoras entrevistadas con hijos no se quieren plantear este dilema, manteniendo lo que podríamos denominar como un "perfil bajo" para sus empresas. Esta estrategia no presupone un carácter menos competitivo ni menos ambicioso por parte de las mujeres frente a los hombres emprendedores, sino la asunción de sus responsabilidades familiares en mayor medida que sus homólogos masculinos (EME1, EME2, EME3, EME5, EME6).

Por parte de los hombres emprendedores, algunos muestran dudas sobre estas estrategias más arriesgadas, como la introducción de capital riesgo o de socios externos. Pero estas dudas no van relacionadas con las posibles implicaciones respecto a la relación entre familia y empleo, sino más bien a las consecuencias que tendrían estas inversiones externas en el propio control de la empresa y su situación futura (EHE1, EHE2, EHE3, EHE4, EHE5). Este discurso incluso se acaba interiorizando en algunos y algunas entrevistadas, llegando a definir a los hombres emprendedores como personas más agresivas, competitivas y arriesgadas, frente a las mujeres emprendedoras como personas más conservadoras y menos competitivas (EME9, EME10). Discurso que reproduce los estereotipos masculinos y femeninos aparecidos en las entrevistas a mujeres investigadoras, ya apuntado al principio de este apartado.

En la encuesta realizada, dos preguntas proporcionan algunas pistas sobre estas estrategias diferenciadas en función del género. La primera interroga sobre las formas de financiación inicial de la empresa. La segunda versa sobre las condiciones que emprendedores y emprendedoras consideran más adecuadas para crear una empresa. Respecto a las formas de financiación inicial de las empresas estudiadas (Tabla 3), encontramos ciertas diferencias en función del género. La primera observación es que el $82,4 \%$ de los hombres han contestado en alguna de las dos opciones posibles que una de sus fuentes de financiación fueron los ahorros propios. Este porcentaje baja hasta el $66,7 \%$ para el caso de las mujeres, lo que supone una mayor capacidad propia de los hombres emprendedores respecto a sus homólogas femeninas. El otro factor también a considerar es la mayor presencia para el caso de los hombres de fondos de financiación vinculadas a créditos bancarios (con o sin avales) con un $19,8 \%$ y con inversiones de sociedades de capital riesgo, con un $17,6 \%$, lo que nos puede indicar dos cuestiones. La primera, que esta financiación esté vinculada a una estrategia inicial más agresiva por parte de los hombres emprendedores respecto a su negocio. La segunda cuestión hace referencia al tipo de empresa, de actividad y de mercado competitivo en donde se inicia el negocio empresarial. Para las empresas dirigidas por mujeres, los créditos bancarios con o sin avales también suponen una fuente importante de financiación inicial junto con los propios proveedores y clientes, ambos con un $33 \%$ de casos. 
TABLA 3. Financiación inicial (dos opciones) según género

\begin{tabular}{|l|c|c|}
\hline \multirow{2}{*}{\multicolumn{1}{c|}{ Financiación inicial }} & \multicolumn{2}{c|}{ Porcentaje de casos } \\
\cline { 2 - 3 } & Hombre & Mujer \\
\hline Ahorros propios & 82,4 & 66,7 \\
Ahorros de familiares & 8,8 & 0 \\
Ahorros de amigos & 5,9 & 0 \\
Créditos bancarios sin avales & 8,8 & 0 \\
Créditos bancarios con avales personales & 11,8 & 33,3 \\
Proveedores y clientes & 5,9 & 33,3 \\
Sociedades de capital riesgo & 17,6 & 0 \\
Otros & 26,5 & 0 \\
\hline
\end{tabular}

Los porcentajes se basan en el número de casos.

Fuente: Elaboración propia.

Respecto a las condiciones necesarias para crear una empresa (Tabla 4), también encontramos ciertas diferencias entre emprendedores y emprendedoras. Mientras que la mayoría de los hombres consideran la iniciativa individual como la condición principal para poder crear una empresa, las mujeres emprendedoras diversifican sus respuestas. Así, la creatividad es, según ellas, la condición principal (con un $33,3 \%$ ), seguida de la iniciativa individual, la formación empresarial y el espíritu de riesgo, todos con un 16,7\%.

TABLA 4. Condiciones para crear una empresa según género (porcentajes)

\begin{tabular}{|l|c|c|c}
\hline Condiciones de creación de una empresa & Hombre & Mujer & Total \\
\hline Iniciativa individual & 66,7 & 16,7 & 59 \\
Creatividad & 6,1 & 33,3 & 10,3 \\
Formación empresarial & 6,1 & 16,7 & 7,7 \\
Espíritu de riesgo & 12,1 & 16,7 & 12,8 \\
Apoyo amical/familiar & 6,1 & 0 & 5,1 \\
Otros & 3 & 16,7 & 5,1 \\
Total & 100 & 100 & 100 \\
\hline
\end{tabular}

Fuente: Elaboración propia. 


\section{Conclusiones}

Uno de los objetivos de esta investigación era estudiar cómo la división sexual del trabajo condicionaba en gran medida la mayor o menor presencia de mujeres responsables de empresas spin-off. De los resultados de esta investigación se deriva que la relación entre el ámbito productivo y reproductivo resulta crucial a la hora de condicionar las trayectorias profesionales de las mujeres investigadoras y de su posible "salto" al mundo de la empresa.

Los resultados obtenidos en la fase exploratoria se han visto confirmados con las siguientes fases realizadas. En este sentido, se ha observado como uno de los elementos que condicionan este salto a la iniciativa privada es el posible cambio en la organización de las responsabilidades familiares entre hombres y mujeres y sus respectivas parejas. Hablamos, en definitiva, de cambios en la división sexual del trabajo a pequeña escala o, si se quiere, a nivel familiar. El apoyo institucional también resulta decisivo, sea éste del grupo de investigación y en menor medida del departamento y de otras estructuras universitarias como las oficinas de transferencia e innovación o equivalentes. Pero se observa una menor incidencia respecto al factor familiar. En esta línea, las mujeres emprendedoras manifiestan un apoyo de su entorno familiar más intenso que en el caso de sus homólogos masculinos. Éstos, en cambio, tienen en su entorno amical y laboral un soporte mayor que las mujeres emprendedoras. Así lo muestra la encuesta realizada (Gráficos 8 y 9), cuando se pregunta por el apoyo inicial, observándose un mayor apoyo por parte del entorno familiar más próximo (pareja y padres) de las mujeres y un mayor apoyo del entorno amical y laboral de los hombres. Las entrevistas realizadas confirman la importancia del factor pareja en la experiencia de las mujeres emprendedoras entrevistadas.

Por otro lado, no se ha observado una especial incidencia del trabajo por cuenta propia en la mayor o menor conciliación o, si se quiere, compatibilidad de la vida laboral y familiar por parte hombres y mujeres. Al contrario, las mujeres emprendedoras siguen responsabilizándose mayoritariamente del cuidado y atención de su hogar y de su familia, tal y como muestra la encuesta (Gráficos 4 y 5). Lo que sí se ha observado es una serie de características particulares de las empresas dirigidas por mujeres emprendedoras, como es la adopción de estrategias empresariales más conservadoras o, si se quiere, más "modestas" en sus objetivos económicos a alcanzar, respecto a sus homólogos masculinos. La asunción de sus responsabilidades familiares por parte de las propias emprendedoras parece también tener cierta incidencia en la propia organización del trabajo dentro de sus empresas. El culto al denominado "presentismo laboral" no parece tener un excesivo éxito en estas empresas. Las mujeres emprendedoras con familia e hijos son conscientes y responsables de que tienen "otra vida" más allá de su empresa y este pensamiento les permite ser más sensibles frente a la gestión de su empresa y frente a sus trabajadores y trabajadoras. Los resultados de esta investigación aportan una serie de ele- 
mentos interesantes a explorar con una mayor atención en un futuro y que nos pueden aportar más luz sobre la relación entre la división sexual del trabajo y su incidencia sobre la creación de empresas y, más específicamente, la creación de empresas spin-off.

\section{Referencias bibliográficas}

Acs, Z.. Arenius, P., Hay, M. y Minniti, M. 2005. Global Entrepreneurship Monitor. Executive Report 2004. Babson Park: Babson College and London Business School.

Álvarez, S. A. y Meyer, G. D. 1998. "Why do women become entrepreneurs?" Frontiers of Entrepreneurship Research 63 (4):83-98.

Amin, A. y Thrift, N. 1994. "Living in the global". En Globalization, institutions and regional development in Europe, editado por Amin, A. y Thrift, N. Oxford: Oxford University Press.

Arenius, P. y Minnitti, M. 2003. "A cross-country study of gender differences in selfemployment. A preliminary draft," Comunicación presentada al 1st GEM Research Conference, 1-3 abril, Berlín.

Audretsch, D., Hulsbeck, M. y Lehmann, E. 2012. "Regional competitiveness, university spillovers". Small Business Economics, 587: 162-188.

Baines, S. y Wheelock, J. 2000. "Work and employment in small business: Perpetuating and challenging gender traditions". Gender, Work and Organizations 7 (1): 45-56.

Baines, S., Wheelock, J. y Gelder, U. 2003. Riding the roller coaster family life and selfemployment. Cambridge Policy Press/Joseph Rowntree Foundation.

Berg, N. G. 1997. "Gender, place and entrepreneurship". Entrepreneurship \& Regional Development 9: 259-268.

Berman, E. P. 2008. "Why Did Universities Start Patenting? Institution-building and the Road to the Bath-Dole Act". Social Studies of Science 38 (6), 36-58.

Boden, R. J. 1999. "Flexible working hours, family responsibilities and female selfemployment." American Journal of Economics and Sociology 58 (1): 71-84.

Brunet, I. y Cincunegui, C. 2010. Desarrollo regional. Madrid: Entinema.

Brunet, I. y Böcker, R. 2007. Desarrollo, industria y empresa. Madrid: Tecnos.

Brunet, I. y Böcker, R. 2008. "Espacio, desarrollo y localización industrial." Praxis Sociológica 12, 173-194.

Brunet, I. y Böcker, R. 2010. "Políticas de desarrollo endógeno: una perspectiva histórica". Inguruak 47.

Brunet, I., Belzunegui, A. y Valls, F. 2009. Gènere i creació d'empreses a Catalunya. Tarragona: Publicaciones URV.

Brush, C. G., Carter, N., Gatewood, E., Greene, P. y Hart, M. 2004. Clearing the hurdles: Women building high-growth businesses. Upper Saddle River: Prentice Hall.

Chinchilla, M. N. 1997. "¿Cómo emprenden las mujeres? Motivaciones y competencias distintivas". Iniciativa Empresarial y Empresa Familiar 13: 11-16.

Clark, B. R. 1998. Creating entrepreneurial universities organizational pathways if transformation. New York: IAU Press. 
Clarysse, B., Moray, N. y Heirman, A. 2002. "Transferring technology by spinning off ventures: Towards an empirically based understanding of the spin off process". Universidad de Cent, Working Paper, enero 2002/1.

Connely, R. 1992. "Self-employment and Providing Child Care". Demography 29(1): 17-29.

CRUE 2007. Informe RedOTRI2007. RedOTRI Universidades. Consulta 23 de abril de 2012. (http://www.redotriuniversidades.net/)

CRUE 2012. Informe de la encuesta de investigación y transferencia de conocimiento 2011 de las universidades españolas. RedOTRI Universidades. Consulta 18 de junio de 2013. (http://www.redotriuniversidades.net/)

D'Este, P. y Perkmann, M. 2011. "Why do academias engañe with industry? The enterpreneurieal university and individual motivations". The Journal of Technology Tranfer. 316: $38-52$.

Etzkowitz, H. 2002. "El auge de la Universidad emprendedora". Estocolmo: 21-23.

Etzkowitz, H. 2003. "Research groups as 'quasi firms': the invention of the entrepreneurial university". Research Policy 32: 109-121.

Etzkowitz, H., Webster, A., Gebhardt, C., y Cantisano, B. R. 2000. "The future of the University and the University of the future: evolution of ivory tower into entrepreneurial university". Research Policy 29: 313-330.

Ferguson, F. E. y Durup, J. R. 1997. "Work-family conflict and entrepreneurial women: A literature review." Journal of Small Business and Entrepreneurship 14 (1): 46-57.

Florida, R. 2000, "The Learning Region". En Regional Innovation, Knowledge and Global Change, editado por Acs, Z. Londres: Pinter.

Freeman, C. y Pérez, C. 1997. The economic of Industrial Innovation. The MIT Press.

Gardiner, J. 1997. Gender, Care and Economics. Londres: MacMillan Press Ltd.

GEM (varios años). Informe Ejecutivo GEM España, disponible en http://www.ie.edu/gem.

Godin, B. y Gingras, Y. 2000. "The place of universities in the system of knowledge production". Research Policy 2: 273-278.

Greenhaus, J. y Parasuraman, S. 1999. "Research on work, family and gender: Current status and future directions». En Handbook of Gender and Work, editado por Powell, G. Londres: Sage.

Guerrero, M. y Urbano D. 2012. "The development o fan enterpreneurial unviersity". The Journal of Technology Transfer, 32: 35-46.

Hayes, D. y Wynyard; R. eds. 2002. The McDonalization of Higher education. Westport, CT: Bergin and Garvey.

Henderson, R., Jaffe, A.B. y Trajtenberg, M. 1998. "Universities as a Source of Commercial Technology". Review of Economics and Statistics 80: 119-127.

Hildebrand, V. y Williams, D.R. 2003. Self-employment and Caring for Children, IRISS-C/I Working Paper 2003-06, EPS/INSTEAD, Differdange, Luxemburgo.

Hollingsworth, J. R. y Boyer, R. 1997. "Coordination of Economic and Social Systems of Productions". en Contemporary capitalism. The embeddedness of institutions, coordinado por Hollingsworth, J. R. y Boyer, R. Cambridge University Press.

Moore, K. y Friekel, S. eds. 2007. The New Political Economy of Science: Institutions, Networks, Power. Michigan: University of Wisconsin Press. 
Nelles, J. y Vorley, T. 2011. “Enterpreneurial Architecture: A Blueprint for Enterpreneurial Universities". Canadian Journal of Administrative Sciences, 341: 241-261.

OCDE 1996. The Knowledge Based Economy. Paris: OCDE.

OCDE 1997. Women Entrepreneurs in SMEs: A Major Force in Innovation and Job Creation, Synthesis of the OECD Conference. Disponible en http://www.oecd.org.

OCDE 1999. "Key messages from the thematic review of entrepreneurship". OECDTerritorial Development Service. Paris: OCDE.

OCDE 2000. A New Economy? The Changing Role of Innovation and Information Technology in Growth. Paris: OCDE.

OCDE 2001. Women Entrepreneurs in SME. Realizing the benefits of Globalizing and the Knowledge-based Economy. Paris: OCDE.

OCDE 2003. Entrepreneurship and Local Economic Development through Entrepreneurship. Paris: OCDE.

O'shea, R.P., Allen, T.J., Chevalier, A. y Roche, F. 2005. “Entrepreneurial Orientation, Technology Transfer and Spin-Off Performance of U.S. Universities". Research Policy 34 (7): 994-1009.

Parker, S. 2004. The Economics of Self-Employment and Entrepreneurship. Cambridge, UK: Cambridge University Press.

Reynolds, P. D., Michael, S., Bygrave, W. y Autio, M. 2002. Global Entrepreneurship Monitor. Kansas City: Kaufman Center.

Rodeiro Pazos, D., Fernández López, S., Rodríguez Sandiás, A. y Otero González, L. 2008. La creación de empresas en el sistema universitario español. Santiago de Compostela: Universidade de Santiago de Compostela.

Rodeiro Pazos, D., Fernández López, S., Rodríguez, A. y Otero González, L. 2010. “Factores determinantes de la creación de spin-offs universitarias". Revista Europea de Dirección y Economía de la Empresa 1: 47-68.

Rodríguez, A., Fernández, S., Rodeiro, D. y Otero, L. 2005. “El papel de las universidades en la sociedad del conocimiento: una propuesta de indicadores". XV Jornadas Hispano-Lusas de Gestión Científica, Sevilla.

Rosa, P. y Hamilton, D. 1994. "Gender an ownership in UK small firms". Entrepreneurship: Theory \& Practice 18 (3): 11-28.

Scott, A. J. y Storper, M. 2003. "Regions, globalization, development". Regional Studies, 6- 7: 579-593.

Shaw, E., Carter, S. y Brierton, J. 2001. Unequal entrepreneurs: Why female enterprise is an uphill business. Londres: The Industrial Society.

Shelton, L. 2006. "Female entrepreneurs, work-family interface". Journal of Small Business Management 44 (2): 285-297.

Shinnar, R., Giacomin, O. y Janssen, F. 2012. "Enterpreneurial Perceptions and Intentions: The Role of Gender and Culture". Baylor Unviersity, 29: 67-84.

Storper, M. 1995. "The resurgence of regional economies, ten years later: The regions as nexus of untraded interdependencies". European Urban Regional Studies 2: 191-221.

Storper, M. 1998. The Regional World. Territorial Development in a Global Economy. Nueva York: Guilford Press. 
Torns, T. 2005. "De la imposible conciliación a los permanentes malos arreglos". Cuadernos de Relaciones Laborales 23 (1): 15-33.

Ussman, A. y Postigo, S. 2000. O Papel da Universidade no Fomento da Funçao Empresarial, Anais Universitarios. Ciencias Sociais e Humanas, 1990-2000 Yearbook Special Issue.

Verheul, I. y Thurik, A. 2001. "Start-up capital: Differences between male and female entrepreneurs: Does gender matter?" Small Business Economics 16 (4): 329-345.

Vesper, K. y Gartner, W. 1997. "Measuring Progress in Entrepreneurship Education". Journal of Business Venturing 12(5): 403-421.

Williams, F. 2004. Rethinking Families. Londres: Calouste Gulbenkian Foundation. 


\section{ARTICULOS/ARTICLES}

Empresas spin-off y género: diferencias entre hombres y mujeres en la creación de empresas de base tecnológica / Spin-off and gender: differences between men and women in the creation of technology-based companies

Ignasi Brunet Icart y Joan Rodríguez Soler

Custodia compartida: atribución vivienda familiar / Shared custody: the acquisition the family living Beatriz Escudero Berzal

Aproximación al estado de bienestar en Polonia / Aproximation to the welfare state in Poland Paloma Serrano Postigo

Menores víctimas de la violencia de género: propuesta de proyecto educativo / Minours who are victims of gender-violence. Proposal for an educational project

Luis Manuel Rodríguez Otero

La obesidad paradójica: construcción de una imagen corporal contradictoria / Paradoxical obesity: building a contradictory body image

Martha Leticia Cabello Garza y María Concepción Arroyo Rueda

\section{RESENAAS/REVIEWS}

Del Fresno García, M., Segado Sánchez-Cabezudo, S., López Peláez, A. (eds). Trabajo social con comunidades en el siglo XXI / Social Work with communites in the XXI Century (por Yolanda Meneses García)

Sagrario Segado Sánchez-Cabezudo, Miguel del Fresno García y Antonio López Peláez (eds.). Modelos de Trabajo Social con grupos: nuevas perspectivas y nuevos contextos / Models of social work with groups: new perspectives and new contexs (por Emilio Díaz de Mera)

Antonio López Peláez (ed.) The Robotics Divide: a New Frontier in the 21st Century? / La brecha robótica: ¿una nueva frontera en el siglo XXI? (por Raquel Pérez García)..... 